J. Clin. Chem. Clin. Biochem.

Vol. 25, 1987, pp. $431-435$

(C) 1987 Walter de Gruyter \& Co. Berlin - New York

\title{
Radioelectrophoresis for Determination of Thyroid Hormone Binding Abnormalities in Human Serum
}

\author{
By Beate Leopold, O. Wawschinek
}

Institut für Medizinische Biochemie Universität Graz,

\author{
P. Lind and $O$. Eber
}

Krankenhaus der Barmherzigen Brüder, Graz, Österreich

(Received January 5/March 25, 1987)

Summary: This paper describes a rapid and accurate method for detèrmining binding abilities of thyroid hormones to their corresponding serum proteins: prealbumin, albumin and thyroxine binding globulin. A tube cell agarose gel electrophoresis is used with radioactive labelled triiodothyronine or thyroxine. The distribution curve shows characteristic peaks for prealbumin, albumin and thyroxine binding globulin.

A collective of 60 euthyroid thyroid-healthy persons was examined, and the following reference values for the binding of thyroxine to its binding proteins were found: The percentage binding of thyroxine to the prealbumin fraction is 21 to $33 \%$, to the albumin fraction 10 to $15 \%$ and to the thyroxine binding globulin fraction 54 to $66 \%$. In a group of 220 patients with suspected thyroid hormone binding abnormalities there were 42 cases of albumin-associated hyperthyroxinaemia, 5 cases of prealbumin-associated hyperthyroxinaemia and 2 cases of thyroxine binding globulin deficiency. In another group of 35 patients with suspected antibodies against thyroid hormones one patient showed antibodies against triiodothyronine.

\section{Introduction}

Today, several thyroid hormone binding abnormalities are known.

Albumin-asșociated hyperthyroxinaemia was first described in $1979(1 \div 6)$. The genetic studies show an autosomal-dominant inheritance called FDH syndrome (familiar dysalbuminaemic hyperthyroxinaemia). The syndrome is characterized by an increase in serum total thyroxine $\left(\mathrm{TT}_{4}\right)$, the free thyroxine index $\left(\mathrm{FT}_{4} \mathrm{I}\right)$ and elevated free $\mathrm{T}_{4}\left(\mathrm{fT}_{4}\right)$ measured by analogue tracer, due to an abnormal serum albumin which preferentially binds thyroxine. The euthyroid state is characterized by a normal $\mathrm{fT}_{4}$ (determined by equilibrium dialysiss) and by a normal serum thyrotropin (TSH) response to thyroliberin (TRH).

A thyroxine binding abnormality for prealbumin (TBPA) was subsequently reported by Moses et al. 1982 (7) and Lalloz et al. 1984 (8).
Thyroxine binding globulin (TBG) elevations during pregnancy or oral contraception, familial thyroxine binding globulin excess with X-linked inheritance (9) and thyroxine binding globulin deficiency (10) have been described.

Another binding abnormality concerns the binding of triiodothyronine $\left(\mathrm{T}_{3}\right)$ and thyroxine $\left(\mathrm{T}_{4}\right)$ to antibodies of the IgG class (11). On the whole, the occurrence of thyroid hormone antibodies is rare and usually found in patients with Hashimoto thyreoiditis, thyroid cancer and Graves' disease. In these cases there is a $70 \%$ occurrence of antibodies against $T_{3}$, $20 \%$ of antibodies against $T_{3}$ and $T_{4}$ and $10 \%$ of antibodies against $T_{4}$ only (12).

These alterations in thyroxine binding proteins lead to changes in thyroid function tests resulting in erroneous diagnosis of thyroid dysfunction in euthyroid individuals. It is therefore very important to deter- 
mine the binding of $T_{3}$ and $T_{4}$ to their binding proteins thyroxine binding prealbumin, albumin and thyroxine binding globulin.

The object of our work was the development of a rapid and accurate new method, applicable in a routine laboratory, for the determination of thyroid hormone binding to serum proteins.

\section{Materials}

$\left[{ }^{125}\right.$ I] thyroxine solution (I. M. 141) and [ ${ }^{125}$ I]triiodothyronine solution (I.M. 321) were obtained from Amersham (G.B.), agar purum from Behring (West Germany). All other reagents were purchased from Merck (West Germany) and were of analytical grade.

\section{Methods}

Radioelectrophoresis for determination of thyroxine binding to thyroxine binding prealbumin, albumin and thyroxine binding globulin

Fresh or deep frozen serum $(100 \mu \mathrm{l})$ is incubated with $10 \mu \mathrm{l}$ radioactive labelled $T_{4}$ for 1 hour at room temperature. To stain the albumin, the sera are mixed with $5 \mu$ l of a saturated aqueous bromphenol blue solution. For the preparation of agarose gel, $9 \mathrm{~g}$ agar purum are dissolved in one liter of the following buffer:

$0.17 \mathrm{~mol} / 1$ glycine, $0.13 \mathrm{~mol} / 1$ acetic acid, $0.14 \mathrm{~mol} / 1$ sodium hydroxide, $3.1 \mathrm{mmol} / 1$ sodium azide, $\mathrm{pH}$ 8.6.

The agarose gel is poured into gel tubes. The glass gel tubes used were of $5 \mathrm{~mm}$ interior diameter and $7 \mathrm{~cm}$ length (Bio Rad, USA). The bottom of the tubes are closed by a dialysis membrane to prevent the gels from slipping out. Serum $(5 \mu \mathrm{l})$ is applied to the gel. Electrophoresis is performed in the same buffer as described above at $15 \mathrm{~mA}$ per tube for 105 minutes. (Tube cell electrophoresis with cooling core by Bio Rad, type 175). After electrophoresis, the gels are cut into 20 slices of 2 to $3 \mathrm{~mm}$ width each, and the radioactivity of each slice is measured in a gamma counter. The slice number is plotted ( $x$ axis) against counts per minute (y-axis).

Radioelectrophoresis for determination of thyroid hormone antibodies

Serum $(100 \mu \mathrm{l})$ and $1.5 \mathrm{mg}$ 8-anilinonaphthalene-1-sulphonic acid ammonium salt (ANS) are incubated with $10 \mu \mathrm{l}$ radioactive labelled $T_{3}$ or $T_{4}$ for 24 hours at room temperature. Radioelectrophoresis is then carried out as described above.

\section{Results}

After electrophoresis the gel shows one band which represents the bromphenol blue-stained albumin. The region between albumin and the origin contains the thyroxine binding globulin and the region anodal to albumin contains the thyroxine binding prealbumin. The radiogram of the gel shows peaks for thyroxine binding prealbumin, albumin and thyroxine binding

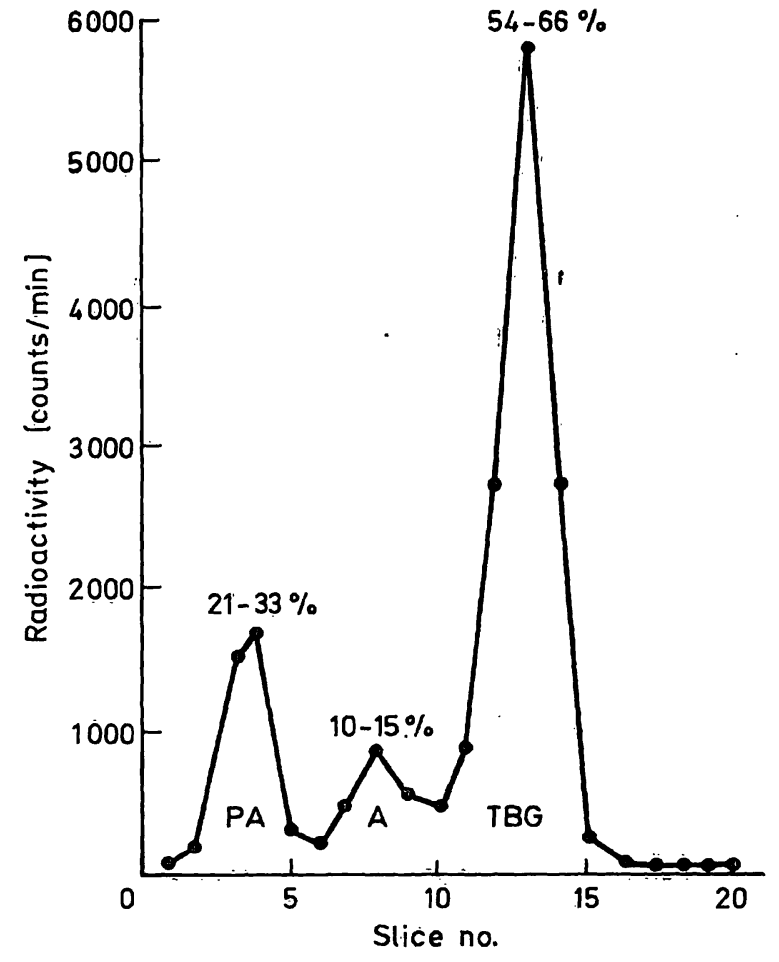

Fig. 1. Normal distribution curve with reference ranges of thyroxine binding to prealbumin (PA), albumin (A) and thyroxine binding globulin (Tत̂).

globulin (fig. 1). The number of counts under each peak shows the binding of radioactive-labelled $\mathrm{T}_{4}$ to thyroxine binding prealbumin, albumin and thyroxine binding globulin in per cent of the total radioactivity.

In the presence of 8-anilinonaphthalene-1-sulphonic acid, thyroid hormone binding to thyroxine binding globulin is suppressed and the binding equilibrium shifts to the thyroid hormone antibodies. A normal distribution curve of $\mathrm{T}_{3}$ incubated with 8-anilinonaphthalene-1-sulphonic acid shows only one albumin peak (fig. 5). In the case of $T_{3}$ antibodies the radiogram shows one peak for albumin-bound $T_{3}$ and one peak in the area of the $\gamma$-globulin fraction (fig. 6). In the case of $T_{4}$ antibodies, a thyroxine binding prealbumin peak, an albumin peak and a peak in the area of the $\gamma$-globulin fraction are seen.

In order to define normal binding patterns of thyroid hormones to their binding proteins, 60 euthyroid thyroid-healthy persons were examined using this new method. The percentage binding of thyroxine to thyroxine binding prealbumin is 21 to $33 \%$, for albumin 10 to $15 \%$ and for thyroxine binding globulin 54 to $66 \%$ (fig. 1). 


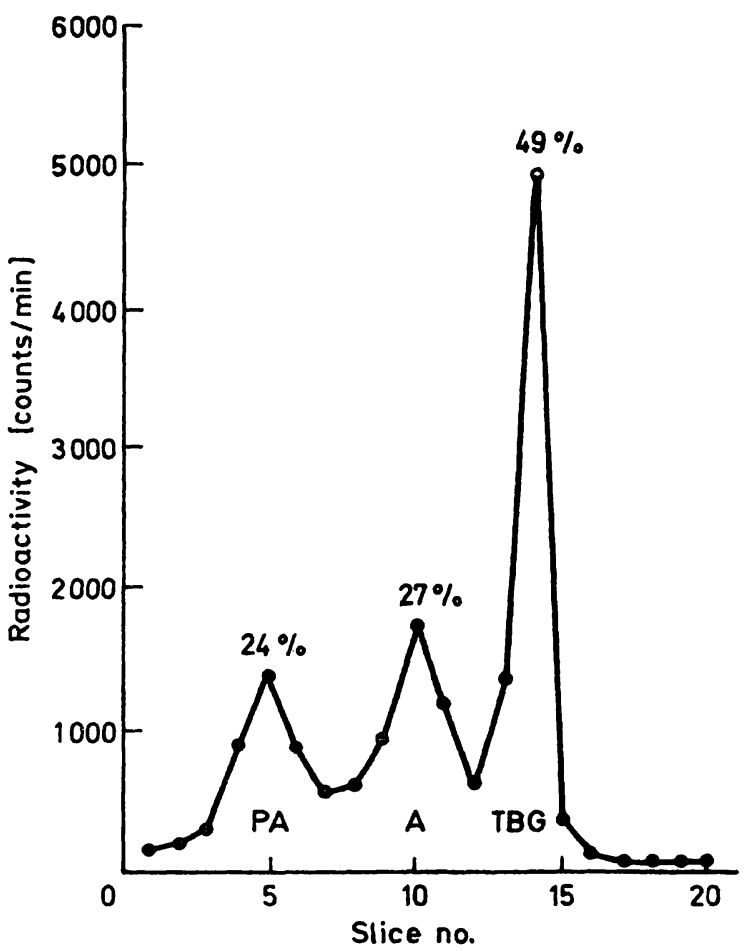

Fig. 2. Albumin-associated hyperthyroxinaemia: binding of thyroxine to albumin $(A)$ is clearly increased at $27 \%$, while binding to prealbumin (PA) is in the normal range, and binding to thyroxine binding globulin (TBG) is decreased.

Furthermore, 220 patients with suspected binding abnormalities were examined.

In 42 cases, an increased binding of $\mathrm{T}_{4}$ to albumin (FDH-syndrome) was found. The percentage binding of $T_{4}$ to albumin was between 19 and $39 \%$. The mean value was $25.5 \pm 4.9 \%$ (fig. 2 ). In connection with albumin-associated hyperthyroxinaemia it is important to examine the entire family because of autosomal dominant inheritance. Of the 42 cases cited above, 24 belonged to 11 families, and 32 members of these families were examined. Thyroxine binding prealbumin-associated hyperthyroxinaemia is rare. Among the same group of patients 5 cases were found. Three cases came from one family. The two others were sporadic. The values of $T_{4}$ bound to thyroxine binding prealbumin were between 36 and $43 \%$ with a mean value of $39.6 \pm 2.9 \%$ (fig. 3 ).

Finally, two cases of thyroxine binding globulin deficiency were found in this collective. Most of the $T_{4}$ is bound to thyroxine binding prealbumin, the rest to albumin: thyroxine binding prealbumin $89 \%$, albumin $11 \%$ and thyroxine binding globulin $0 \%$ (fig. 4). Among the 35 patients with suspected antibodies against thyroid hormones there was one case with antibodies against $T_{3}$ (fig. 6).

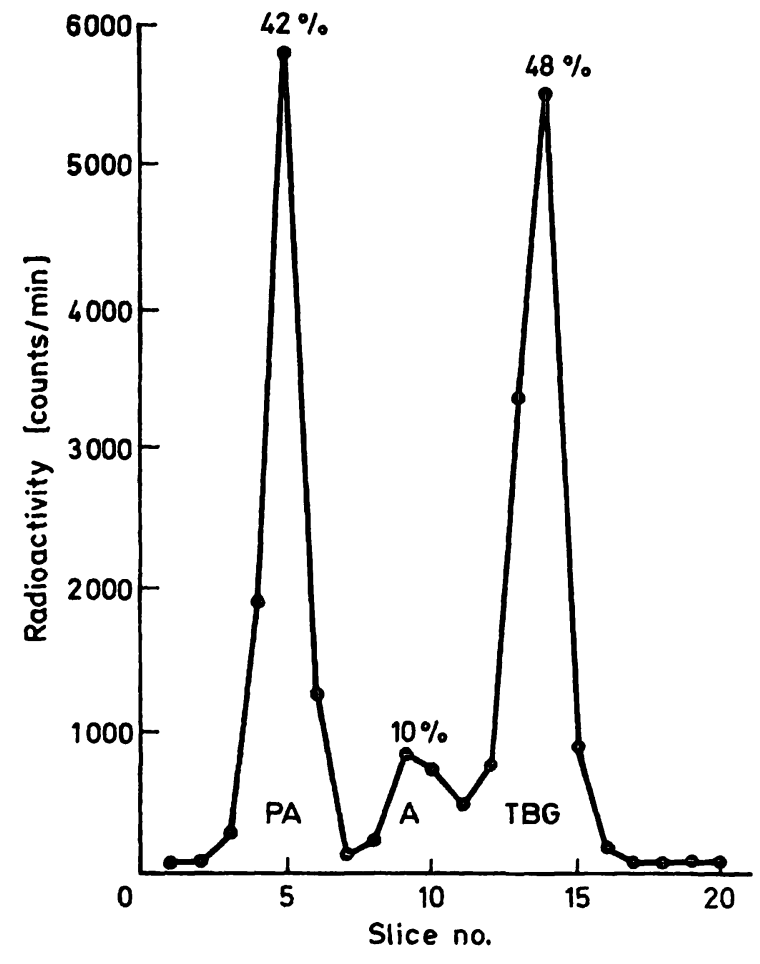

Fig. 3. Prealbumiñ-associated hyperthyroxinaemia: thyroxine binding to prealbumin (PA) is clearly increased, while binding to albumin (A) is in the lower normal range; percentage binding to thyroxine binding globulin (TBG) below reference value at $48 \%$.

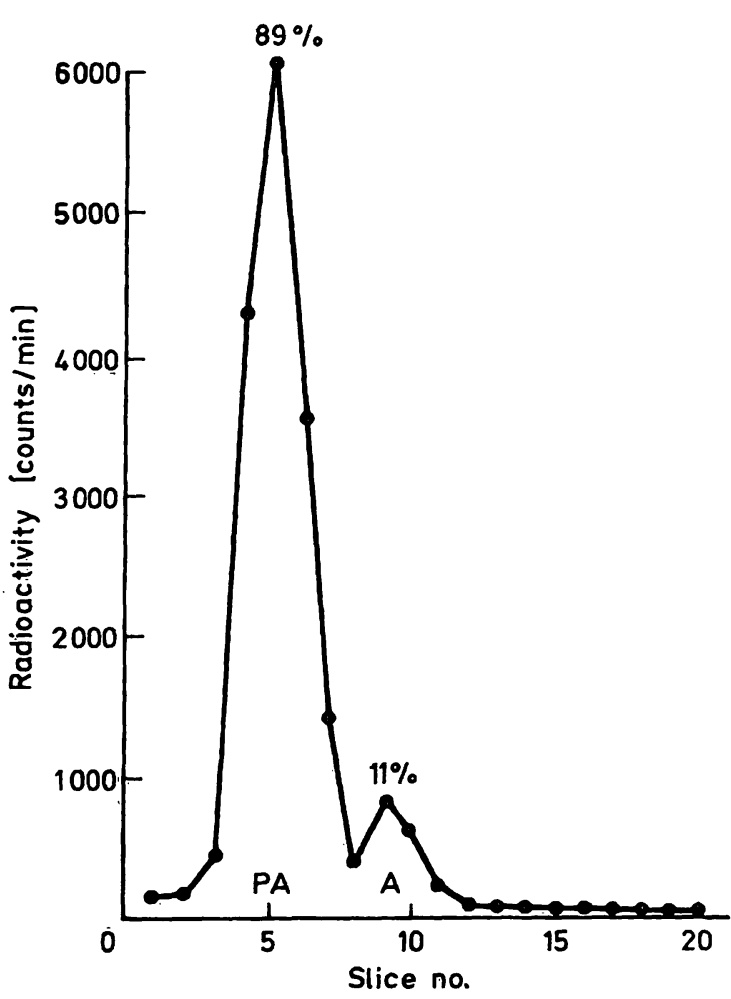

Fig. 4. Thyroxine binding globulin (TBG) deficiency: thyroxine is bound to prealbumin (PA) at $89 \%$ and to albumin (A) at $11 \%$; there is no peak for thyroxine binding globulin (TBG). 


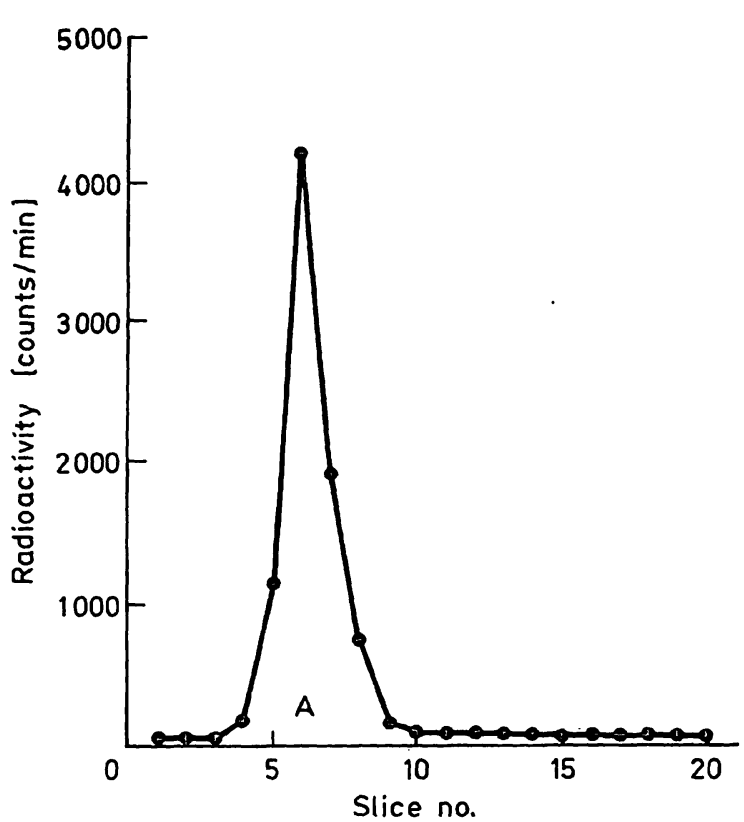

Fig. 5. Normal distribution curve for serum incubated with triiodothyronine and $1.5 \mathrm{mg} 8$-anilinonaphthalene-1sulphonic acid:

The normal curve shows one peak of triiodothyronine bound to albumin (A). The binding of triiodothyronine to thyroxine binding globulin is suppressed by 8 -anilinonaphthalene-1-sulphonic acid.

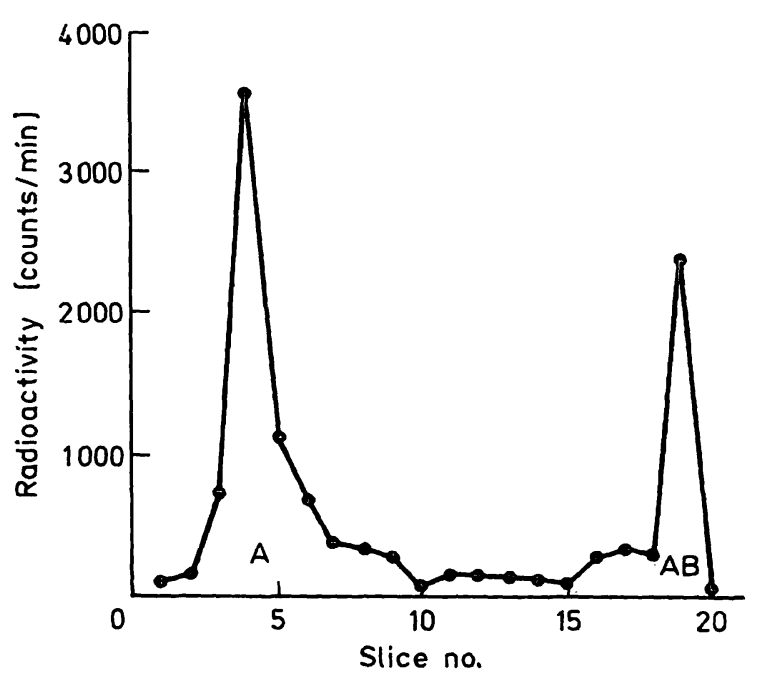

Fig. 6. Antibodies against triiodothyronine:

The serum incubated with triiodothyronine and $1.5 \mathrm{mg}$ 8-anilinonaphthalene-1-sulphonic acid shows an albumin peak (A) and one peak in the $\gamma$-globulin fraction corresponding to triiodothyronine bound to antibodies (AB).

\section{Discussion}

Several methods for measurement of thyroxine binding proteins have been developed. Early attempts with conventional paper electrophoresis failed because of poor separation of the thyroxine binding proteins, and the occurrence of artefacts due to the adsorption of albumin-bound thyroxine on the filter paper. The method was modified by the use of reversed flow zone electrophoresis (13), in which the hydrodynamic flow of buffer opposed the migration of albumin, so that thyroxine binding prealbumin and thyroxine binding globulin were better separated from the albumin. But the technique is time-consuming and the separation is not satisfactory. A better separation was achieved by agarose gel electrophoresis. Doctor et al. 1981 (14) described this technique in agarose gel on microscope slides. A great disadvantage of this method is the necessity for cooling by immersing the slides in petroleum spirit. A second problem is cutting the thin gel into separate sections for counting. These difficulties are largely eliminated by using tube cell agarose gel electrophoresis. Complete separation of the binding proteins is obtained in less than two hours. The cooling of the gels is achieved by the large buffer volume and the water cooling core in the instrument. It is no problem to cut the gel column into several slices for counting.

The normal binding pattern of thyroid hormones to their binding proteins determined by this method does not correspond to values obtained by paper reversed flow zone electrophoresis (3). The results obtained by our method are highly reproducible as assessed by multiple analyses of the same serum sample (results not shown). In clinical practice the described method of binding electrophoresis is an important aid in the diagnosis of euthyroidism. Patients with binding abnormalities show changes in thyroid function tests including increases in $\mathrm{TT}_{4}, \mathrm{FT}_{4} \mathrm{I}$ and analogue $f T_{4}$. As a result of misdiagnosis of hyperthyreosis by use of these conventional methods, 7 of our patients with FDH syndrome underwent surgery or received radio-iodine treatment. Since binding abnormalities are inheritable it is necessary to examine a patient's relatives to prevent misdiagnosis and mistherapy. Such errors have been avoided since the introduction of this new method in routine laboratories. 


\section{References}

1. Hennemann, G., Docter, R., Krenning, E. P., Bos, G., Otten, M. \& Visser, T. J. (1979) Lancet I, 639-642.

2. Barlow, J. W., Csicsmann, J. M., White, E. L., Funder, J. W. \& Stockigt, J. R. (1982) J. Clin. Endocrinol. Metab. 55, 244-250.

3. Borst, G. C., Premachandra, B. N., Burman, K. D., Osburne, R. C., Georges, L. P. \& Johnsonbaugh, R. E. (1982) Am. J. Med. 73, 283-289.

4. Docter, R., Bos, G., Krenning, E. P. \& Hennemann, G. (1984) Lancet $I, 50$.

5. Lalloz, M. R. A., Byfield, P. G. H. \& Himsworth, R. L. (1983) Clin. Endocrinol. 18, 11-24.

6. Stockigt, J. R., Dyer, S. A., Mohr, V. S., White, L. E. \& Barlow, J. W. (1986) J. Clin. Endocrinol. Metab. 62, $230-233$.
7. Moses, A. C., Lawlor, J., Haddow, J. \& Jackson, I. M. D. (1982) N. Engl. J. Med. 306, 966-969.

8. Lalloz, M. R. A., Byfield, P. G. H. \& Himsworth, R. L. (1984) Clin. Endocrinol. 21, 331-338.

9. Penhaligon, J. \& Wellby, M. I. (1982) Acta Endocrinol. 99, 393-396.

10. Nikolai, T. F. \& Roberts, R. C. (1969) Arch. Intern. Med. 124, $691-694$.

11. Ginsberg, J., Segal, D., Ehrlich, R. M. \& Walfish, P. G. (1978) Clin. Endocrinol. 8, 133-139.

12. Reiners, Chr. (1986) Dtsch. Med. Wochenschr. 111 , 1292-1299.

13. Premachandra, B. N. \& Blumenthal, H. T. (1967) J. Clin. Endocrinol. 27, $931-936$.

14. Docter, R., Bos, G., Krenning, E. P., Fekkes, D., Visser, T. J. \& Hennemann, G. (1981) Clin. Endocrinol. 15, 363-371.

Dr. Beate Leopold

Institut für Medizinische Biochemie

Universität Graz

Harrachgasse 21/III

A-8010 Graz 
